\title{
Percepciones de las personas docentes para el mejoramiento de la mediación pedagógica en el uso de videoconferencias en la Universidad Estatal a Distancia (UNED)
}

\section{Teacher's perceptions for pedagogical mediation in videoconferences at Universidad Estatal a Distancia (UNED)}

\author{
Silvia Salas González \\ Académica, Centro de Investigaciones en Educación \\ Universidad Estatal a Distancia \\ San José, Costa Rica \\ ssalasg@uned.ac.cr
}

Recibido - Received: 14 / 08 / 2019 Corregido - Revised: 13 / 02 / 2020 Aceptado - Accepted: 06 / 03 / 2020

DOI: https://doi.org/10.22458/ie.v22i32.2992

URL: https://revistas.uned.ac.cr/index.php/innovaciones

\begin{abstract}
Resumen: El artículo analiza la importancia de que quienes imparten videoconferencias en la Universidad Estatal a Distancia (UNED) sean conscientes de la necesidad de replantearse las estrategias metodológicas propuestas por ellos en el desarrollo de cada una de las sesiones programadas. Por ende, la investigación cumple por objetivo diseñar una propuesta de videoconferencia como recurso para la mediación pedagógica, la cual las personas docentes puedan consultar e implementar en su respectiva planificación. Para tal efecto, el marco teórico se sustentó en la investigación-acción de tipo cooperativa y colaborativa, en la cual se realiza un trabajo conjunto entre investigadores y docentes. El hallazgo principal demuestra la necesidad que manifiestan las personas docentes acerca de recibir procesos de inducción y capacitaciones para planificar y mediar adecuadamente las videoconferencias. Igualmente, que es preciso contar con una guía amplia de elementos técnicos y estrategias pedagógicas útiles para presentar en forma atractiva las temáticas en estudio.
\end{abstract}

Palabras clave: educación a distancia, aprendizaje, tecnologías de la información, capacitación, pedagogía, material didáctico

Summary: The article analyzes the importance that those who give videoconferences at the State Distance University (UNED) should be aware of the need to rethink the methodological strategies proposed by them in the development of each of the scheduled sessions. Therefore, the research aims to design a videoconference proposal as a resource for pedagogical mediation, which teachers can consult and implement in their respective planning. For this purpose, the theoretical framework was based on cooperative and collaborative action research, in which joint work is carried out between researchers and teachers. The main finding demonstrates the need expressed by teachers about receiving induction processes and training to plan and adequately mediate videoconferences. Likewise, it is necessary to have wide guidelines of technical elements and useful pedagogical strategies to present the topics under study in an attractive way.

Keywords: distance education, learning, information technology, training, pedagogy, didactic material 


\section{INTRODUCCIÓN}

Las transformaciones y los avances vertiginosos de las tecnologías de la comunicación e información (TIC) han fomentado el origen de nuevos contextos, sobre todo en aquellas instituciones de educación superior a distancia, gracias al incremento de espacios virtuales de aprendizaje en los que el usuario puede interactuar de forma innovadora y dinámica con las personas docentes y el resto del estudiantado.

Por tal razón, las tecnologías se han convertido en un apoyo fundamental en los procesos educativos que la persona tutora lleva a cabo, pues le permite promover, desencadenar y acompañar el aprendizaje mediante el uso de metodologías flexibles y adaptadas a las necesidades del estudiantado a su cargo. De igual forma, el estudiantado tiene la posibilidad de experimentar una nueva forma de aprendizaje en la que su rol es totalmente activo y en el cual se estimula, vía diferentes actividades, la resolución de problemas, el análisis de casos, el razonamiento y el uso de la lógica, el intercambio de experiencias, de opiniones y la creatividad, entre otras estrategias de aprendizaje.

Los hallazgos relacionados con el tema de la mediación pedagógica en las videoconferencias demuestran que en otros contextos de la educación superior las personas docentes a cargo del recurso se encuentran con factores que deteminan su calidad. Las investigaciones se describen a continuación.

Bonfill (2007) presenta los procesos de comunicación entre el estudiantado y la persona docente. Así, el docente debe encontrar las estrategias apropiadas para que el desarrollo de la videoconferencia no se interrumpa, a pesar de la falta de respuesta de las personas participantes: el entorno físico debido a que la persona docente debe permanecer sentada la mayor parte de la transmisión y levantarse solamente en el receso o al finalizar la sesión; la falta de un pizarrón como recurso; el estado de ánimo y la falta de preparación para impartir videoconferencias.

Por su parte Álvarez, Ochoa, Salado y Soto (2013) llevaron a cabo una investigación con el fin de determinar si el uso de la videoconferencia en la educación superior a distancia está contribuyendo en la mejora de la calidad de los aprendizajes. Los resultados obtenidos evidencian que la efectividad depende de la presencia de factores estructurales entre los que se destacan la interacción entre las personas participantes y la persona tutora, la cantidad de estudiantado por sala y el fácil acceso al material de aprendizaje que utilizará en cada sesión.

Con respecto a los factores organizacionales, mencionan la coordinación para llevar a cabo cada sesión; la estructura del contenido; los materiales apropiados para motivar al estudiantado y la capacidad de la persona docente para planificar, organizar y controlar el curso asignado. En cuanto al currículo, es fundamental que la persona docente cuente con la capacitación adecuada en el uso de las tecnologías y en las habilidades propicias para que presente la información de forma efectiva y en uso de distintos recursos. Por último, se comprobó en este estudio que la videoconferencia es más efectiva si se cuenta con las conexiones, las herramientas, los accesorios y las personas técnicas idóneas para atender y brindar soporte en cada una de las transmisiones.

De igual forma, Knipe y Lee (citados en Álvarez, Ochoa, Salado y Soto, 2013) exponen algunos elementos que interfieren en la calidad de la videoconferencia: la escasa preparación, la inexperiencia, la falta de planificación, fallas como producto de problemas técnicos y no contar con buenas conexiones, entre otras causas.

En síntesis, la videoconferencia es un excelente recurso siempre que se utilice adecuadamente y las autoridades de las instituciones donde se implementa destinen los recursos necesarios para eliminar, o al menos minimizar, el impacto que los factores evidenciados en las investigaciones citadas producen en la calidad de la tecnología. 


\section{MARCO TEÓRICO}

La mediación pedagógica se relaciona con el modo en que la persona docente desarrolla su práctica educativa; enfatiza especialmente en su metodología de aprendizaje y en el acompañamiento que brinda al estudiantado por medio de los materiales y las actividades que propone en sus clases para que logre asociar el aprendizaje previo con el nuevo. De acuerdo con lo que indican Gutiérrez y Prieto:

Entendemos por mediación pedagógica el tratamiento de contenidos y de las formas de expresión de los diferentes temas a fin de hacer posible el acto educativo, dentro del horizonte de una educación concebida como participación, creatividad, expresividad y relacionalidad. (1999, p. 62)

De acuerdo con la cita anterior, la persona enseñante es esencial para promover espacios de intercambio y construcción de conocimiento. Sin embargo, para lograrlo requiere procesos de constante actualización, análisis y elección de los medios o recursos pedagógicos, de mediación y tecnologías que le ayude a innovar constantemente su práctica docente.

Por consiguiente, en la actualidad se requiere que la persona docente se apropie de las tecnologías de información y comunicación (TIC) como parte del proceso de mediación pedagógica y logre analizar el potencial que el tipo de herramientas ofrece a los procesos de enseñanza y aprendizaje, sobre todo en aquellas instituciones donde se trabaja en modalidad a distancia. Este tipo de herramientas proporciona beneficios significativos en el aprendizaje, como los que expone Salazar (2012, p. 110):

1. Favorece el aprendizaje del estudiantado.

2. Genera mayor nivel de interacción.

3. Contiene diversidad de recursos.

4. Permite: búsqueda de información, discusión de ideas, resolución de problemas, desarrollo colaborativo.

Entonces, resulta claro que el uso de las herramientas tecnológicas de forma eficiente logra desarrollar en el estudiantado competencias individuales que le permitan participar, exponer sus inquietudes, mejorar sus habilidades comunicativas y construir su propio aprendizaje.

Por otra parte, se debe considerar que existen algunas investigaciones que refuerzan la relevancia de la mediación pedagógica en los procesos de enseñanza y aprendizaje: Contreras (1995, pp. 5-15) escribió un artículo con el fin de definir si los términos "enseñanza" y "mediación pedagógica" representan solo dos nombres para referirse a un mismo concepto dentro de un mismo paradigma o si, por el contrario, representan un claro indicador de un cambio de modelo pedagógico. Además, menciona algunas ideas fundamentales:

El trabajo de la persona docente se concreta en la interacción didáctica, la cual constituye una actividad planteada intencionalmente para alcanzar una meta o un objetivo mediante la interacción del individuo o del grupo de estudiantes con la persona docente.

La tarea de la persona docente se define por los objetivos que se desean alcanzar mediante la interacción persona docente- persona alumno y la función que cada uno cumple en este proceso.

De acuerdo con el trabajo de la persona docente, entonces a) la interacción que se desarrolle, b) la interrelación existente y c) los logros generados se identifican como modelos o paradigmas; estos, a su vez, permiten explicar el fenómeno educativo y los problemas que este presenta. Empero, en las aulas 
la práctica que se desarrolla no es otra cosa que la asimilación de elementos novedosos dentro de los viejos enfoques, lo cual constituye una clara evidencia de la resistencia al cambio.

La persona docente requiere oportunidades o espacios que les posibilite reflexionar y analizar la teoría con la práctica docente en el contexto de los enfoques pedagógicos actuales.

Para lograrlo, el mediador pedagógico debe garantizarse que exista previamente la estructura cognoscitiva del estudiantado; que se conozcan los conceptos básicos, que disponga del desarrollo de unas operaciones cognoscitivas que le permitan realizar los procesos intelectuales necesarios; que el estudiantado tenga una actitud favorable hacia la comprensión del tema.

No obstante, requiere el apoyo y la colaboración de la institución en la que labora para enfrentar este gran reto, sobre todo aquellas que son a distancia. Por ejemplo, el modelo pedagógico (UNED, 2007) de la UNED destina un lugar fundamental a la interacción. El documento resalta los beneficios y las ventajas para el estudiantado al proporcionarle un espacio donde pueda desarrollar actividades que le permita relacionar los contenidos con sus experiencias previas; por ende, la importancia de que la persona docente logre plantear ejercicios que le ayude al estudiantado a adquirir nuevas habilidades y elija los más convenientes, "por lo tanto, en la selección de los medios interesa valorar el potencial que ofrecen las nuevas tecnologías de información para el tipo de interacción que se desea". (p. 30)

Por consiguiente, en el caso puntual de la mediación eficaz de la videoconferencia, es fundamental que la persona tutora aproveche las estrategias metodológicas que le ayuden a presentar los contenidos de forma diferente y generen la participación del estudiantado en cada una de las salas habilitadas, por ejemplo: debates, lluvia de ideas, juego de roles, trabajo en grupo, entrevista, estudio de casos y demostraciones (Salinas; Aguaded; Cabero; Barroso; De Benito; Cebrián; Correa; García; Guzmán; Duarte; Martínez; Pérez, A.; Pérez, M.; Prendes; Román; Romero; Sevillano y Tirado; 2006).

Sin embargo, el mediador pedagógico debe garantizarse que exista previamente la estructura cognoscitiva del estudiantado, se conozcan los conceptos básicos, se disponga del desarrollo de unas operaciones cognoscitivas que le permitan realizar los procesos intelectuales necesarios; y que el estudiantado tenga una actitud favorable hacia la comprensión del tema.

\section{METODOLOGÍA}

La metodología aplicada es una modalidad de la investigación-acción cooperativa o colaborativa pues se contó con la participación y el aporte de las personas docentes pertenecientes a la Cátedra de Estudios Generales, quienes imparten videoconferencias desde hace varios años. Los académicos y académicas colaboraron activamente en el diseño de una propuesta útil para el quehacer docente en el ámbito de la educación superior a distancia. De acuerdo con Amorós, Cabrera, Espín, Panchón y Rodríguez (citados por Sandí, 2003)

En la investigación cooperativa, el fin último reside en el desarrollo profesional del docente y en la producción de conocimiento situacional y útil. Adicionalmente, la investigación cooperativa no solo es una potente vía de desarrollo para la formación y el desarrollo profesional del profesorado en todos los niveles académicos, sino también para la formación inicial de los futuros docentes. (p. 174)

Por lo tanto, la finalidad de este trabajo de investigación fue brindarles un espacio para conocer las inquietudes y sugerentes de las personas participantes y tomar estos aportes que sirvan de insumo para elaborar en conjunto una propuesta de uso de la videoconferencia como recurso para la mediación pedagógica. 


\section{Población}

Para la investigación, se invitó a las cuatro personas docentes de las asignaturas Historia de la Cultura; La Ciencia en su Historia; Literatura Costarricense e Identidad Nacional; y Métodos de Estudio a Distancia, con el propósito de que pudieran participar activamente y brindar recomendaciones para mejorar los procesos de mediación con el apoyo tecnológico mencionado. Cada docente cuenta con una especialidad y varios años de experiencia:

- Historia: la profesora que tiene a cargo estas videoconferencias labora hace tres años en la UNED y doce en total como docente. Se le asignaron $3 / 4$ de tiempo para atender gestiones relacionadas con la videoconferencia.

- Filosofía: cuenta con 13 años de impartir videoconferencias y se le asignó 1/4 de tiempo para esta tarea.

- Estudios Sociales: ha impartido videoconferencia durante seis años con una carga asignada de $3 / 4$ de tiempo.

- Literatura: su experiencia en videoconferencia suma seis años y para este fin se le asignó $1 / 4$ de tiempo.

Adicionalmente, se le solicitó la colaboración a una persona docente de la Cátedra de Trabajo Social, quien validó la propuesta preliminar. Para tal efecto, se le facilitó el documento preliminar como guía para planificar e impartir una videoconferencia. De esa forma, basada en esa experiencia, pudo brindar sus observaciones o sugerencia para la mejora.

\section{Categoría de análisis}

Las categorías de análisis fueron derivadas tanto de los objetivos que orientaron la investigación como del trabajo de campo y el análisis e interpretación de los hallazgos. Es decir, se previó el surgimiento de categorías durante el proceso de investigación, las cuales permitieron formular, aplicar, evaluar y replantear la propuesta de uso de la videoconferencia como recurso de mediación pedagógica en la educación superior.

Debido a la relevancia de las categorías de análisis, es fundamental detallar a continuación cada una de ellas, así como los objetivos de los cuales de derivan, a fin de que exista mejor comprensión de los resultados obtenidos a raíz de la investigación. 


\begin{tabular}{|c|c|}
\hline \multirow[t]{2}{*}{ Objetivos } & $\begin{array}{l}\text { General: } \\
\text { Diseñar una propuesta de uso de la videoconferencia como recurso para la mediación pedagó- } \\
\text { gica en la educación superior a distancia, en el caso de las asignaturas del Programa de Estudios } \\
\text { Generales que ofrece la Escuela de Ciencias Sociales y Humanidades de la Universidad Estatal a } \\
\text { Distancia de Costa Rica, } 2014 \text {. }\end{array}$ \\
\hline & $\begin{array}{l}\text { Específicos: } \\
\text { 1. Formular una propuesta de uso de la videoconferencia como recurso para la mediación peda- } \\
\text { gógica en la educación superior a distancia. } \\
2 \text { Aplicar una propuesta de uso de la videoconferencia como recurso para la mediación pedagó- } \\
\text { gica en la educación superior a distancia. } \\
3 \text { Evaluar una propuesta de uso de la videoconferencia como recurso para la mediación peda- } \\
\text { gógica en la educación superior a distancia. } \\
\text { 4. Replantear la propuesta de uso de la videoconferencia como recurso para la mediación peda- } \\
\text { gógica en la educación superior a distancia. }\end{array}$ \\
\hline Categorías de análisis & $\begin{array}{l}\text { 1. Formulación de una propuesta de uso de la videoconferencia como recurso para la mediación } \\
\text { pedagógica. } \\
\text { 2. Aplicación de una propuesta de uso de la videoconferencia como recurso para la mediación } \\
\text { pedagógica. } \\
\text { 3. Evaluación de una propuesta de uso de la videoconferencia como recurso para la mediación } \\
\text { pedagógica. } \\
\text { 4. Replanteamiento de una propuesta de uso de la videoconferencia como recurso para la me- } \\
\text { diación pedagógica. } \\
\text { 5. Videoconferencia }\end{array}$ \\
\hline
\end{tabular}

\section{Recolección de datos}

Se aplicaron varios instrumentos para recolectar la información, su aplicación caracteriza cada una de las etapas que distinguen la investigación. Por esa razón, en el análisis y la interpretación se seguirá el mismo orden y se utilizará la misma denominación de cada una de estas fases de forma simultánea junto con el trabajo de campo, como se muestra a continuación:

1. Preparándose para ingresar al campo: la investigadora inició con la elaboración de los instrumentos para la entrevista (guía y entrevista); y dos tablas para anotar los acuerdos obtenidos entre ella y la colaboradora.

2. Aprendiendo de una limitación mediante el acuerdo entre observadores: para Medinnus (1990, p. 61), se debe completar el siguiente procedimiento para llevar a cabo el acuerdo entre observadores. "Elija a dos observadores para que anoten el comportamiento simultáneamente, sin haber discutido con anterioridad un solo aspecto de la observación. Una vez concluida la observación, compare ambos registros".

Como ya se menciona, se trata de un proceso individual en el que cada una de las personas participantes observa los videos seleccionados de las videoconferencias realizadas en las asignaturas de Estudios Generales, mediante las siguientes características: duración (cada sesión dura entre dos o tres horas), cantidad de videoconferencias programadas durante el cuatrimestre, además de las partes en las que se segmenta cada video; no cuentan con actividades interactivas y son de consulta masiva. Cada una de las personas participantes redacta sus anotaciones; posteriormente, se reúne y comparte con la persona compañera y, finalmente, se elabora un cuadro con los aspectos en que ambas coincidieron. El objetivo de estos acuerdos es definir elementos clave que servirían de insumo para la formalización de las categorías de análisis y la proposición. 
3. Registrando el proceso mediante el diario del investigador: según Taylor y Bogdan (1996):

[...] el diario del investigador puede servir a varios propósitos. En primer lugar, debe contener un bosquejo de los temas examinados en cada entrevista. Así podrá seguir la pista de lo que ya ha sido cubierto y a volver atrás, a conversaciones específicas, cuando quiera seguir desarrollando algún contenido expresado por el informante. En segundo lugar, el diario cumple la función de los 'comentarios del observador' registrados en las notas de campo de la observación participante. (p. 131)

Por lo tanto, su meta es recolectar acontecimientos, percepciones, elementos o limitaciones encontradas en cada una de las etapas.

4. Compartiendo ideas, criterios y sugerencias mediante la entrevista: se aplicó la entrevista semiestructurada, la cual, según indican Hernández, Fernández y Baptista (2008): "se basa en una guía de asuntos o preguntas y el entrevistador tiene la libertad de introducir preguntas adicionales para precisar conceptos u obtener mayor información sobre los temas deseados (es decir, no todas las preguntas están determinadas". (p. 597)

Es decir, la entrevista aplicada en la investigación cumplió una función significativa: conocer de forma individual la opinión y los conceptos por parte de las personas participantes en la investigación. Lo anterior le aporta un valor agregado a la información recolectada porque permitió visualizar la forma en que ellos perciben la videoconferencia y su opinión con respecto a las mejoras que consideran necesarias para optimar el uso de este recurso para la mediación pedagógica en la UNED.

5. Compartiendo experiencias con un colega: en este proceso, participó una persona docente que forma parte de la Cátedra de Trabajo Social, con el fin de que utilizara la propuesta preliminar como una guía para planificar la videoconferencia ya programada y, adicionalmente, la enriqueciera con observaciones o sugerencias. Luego, se coordinó una entrevista, en aras de conocer con más especificidad su criterio en cuanto a la propuesta preliminar existente e incorporar la información sugerida para robustecer la idea.

Análisis de datos: con el fin de recolectar los datos que servirán como insumos para la propuesta, la persona investigadora analizó por separado los datos obtenidos en cada instrumento para triangularlos y, de esta forma, ampliar el trabajo elaborado. El proceso de análisis de los resultados inició con el acuerdo entre observadoras, seguido por la entrevista, las percepciones y las sugerencias brindadas por las personas tutoras.

Asuntos éticos: antes de iniciar la investigación, se les consultó a las personas tutoras si estaban de acuerdo con colaborar y se les explicó con claridad la función que cada uno cumpliría durante el proceso. Seguidamente, se les facilitó una fórmula de consentimiento informado en la que se les detallaba información como: utilidad de la investigación, las tareas que cada uno de los participantes realizaría, la duración del trabajo, la confidencialidad y el derecho de rehusarse a ser parte del proyecto.

\section{RESULTADOS}

Los resultados obtenidos en la recolección de información son producto de la aplicación de los instrumentos, la participación de los docentes que imparten las asignaturas del Programa de Estudios Generales de la UNED y las observaciones que aportó una persona docente de la Cátedra de Trabajo Social, quien además utilizó la propuesta preliminar para planificar e impartir una videoconferencia programada.

Como se mencionó en el apartado anterior, el proceso consta de varias etapas con el objetivo de ensanchar la visión actual relacionada con la videoconferencia y la opinión desconocida, hasta este momento, 
por parte de las personas docentes que la utilizan y cuya versión es fundamental para el mejoramiento de la mediación pedagógica. Ahora bien, ya se explicó en el apartado precedente que se seguirán las mismas etapas, las cuales tienen estrecha relación con los instrumentos aplicados y se detallan de seguido:

\section{1- Preparándose para ingresar al campo}

Para la elaboración de estos instrumentos, se tomaron como referencia algunos elementos extraídos de la literatura consultada, que indican factores como: la importancia de la comunicación entre el educador y el educando, el entorno físico, el uso de apoyos audiovisuales, el tiempo y los factores emocionales que el tutor experimenta durante el desarrollo de toda la videoconferencia y la capacitación recibida para asumir este reto (Bonfill, 2007).

\section{2- Aprendiendo de una limitación mediante el acuerdo entre observadores}

Para evidenciar los acuerdos a los que llegaron la persona investigadora y la persona observadora externa después de observar dos videoconferencias grabadas de los cursos La Ciencia en su Historia e Historia de la Cultura, se elaboraron dos cuadros en los que se clasificaron los insumos en categorías que pueden orientar la mediación pedagógica y sus implicaciones, como se muestra a continuación:

TABLA 1

Acuerdos sobre la videoconferencia de La Ciencia en su Historia

\section{Categorías que pueden orientar la mediación pedagógica}

\section{Implicación en términos de mediación pedagógica}

Al inicio de la videoconferencia, la persona docente abre la posibili- La persona profesora plantea preguntas para incentidad para que el estudiantado formule sus preguntas, comentarios o var la participación del estudiantado.

consultas.

Durante la videoconferencia, la persona docente anticipa los conteni- Contextualiza al estudiantado en los contenidos. dos previos y su relación con la unidad didáctica.

Ubica los contenidos que va a tratar en relación con la unidad Relaciona contenidos y unidad didáctica. didáctica.

La persona docente usa esquemas para presentar y explicar concep- Usa esquemas.

tos básicos de la materia de estudio.

La persona docente debe evitar el uso de las diapositivas cargadas de texto en la videoconferencia.

Evita el exceso de contenidos en cada una de las videoconferencias.

La persona docente desarrolla la explicación de términos en estudio.

La persona docente muestra imágenes alusivas al tema tratado.

Contextualiza términos de acuerdo con el contenido.

La persona docente recapitula y anticipa temas nuevos.

Vincula imágenes con el texto.

Relaciona temáticas complementarias.

Durante la videoconferencia, la persona docente formula ejemplos al estudiantado para una mejor comprensión de los contenidos en estudio.

La persona docente menciona que el estudiantado tiene la concepción de que todos los contenidos desarrollados en la videoconferencia serán evaluados.

Presenta una síntesis y un cierre en cada uno los bloques o módulos grabados.

Con respecto a la grabación de la videoconferencia de Historia de la Cultura, se especifican los siguientes acuerdos.
Presenta los contenidos en la videoconferencia para generar en el estudiantado conocimientos, habilidades y competencias que trascienden los contenidos evaluados por medio de un examen.

Presenta una síntesis de los contenidos. 
TABLA 2

Acuerdos sobre la videoconferencia de Historia de la Cultura

\section{Categorías que pueden orientar la mediación pedagógica}

La persona docente anticipa una variante en la temática.

Desarrolla una contextualización histórica.

Explica el tema de la globalización.

Durante la videoconferencia, la profesora expone conceptos básicos.

La persona docente muestra imágenes y figuras.

La persona docente gesticula con las manos.

La persona docente debe verificar que los gráficos

sean legibles.

Durante la videoconferencia, se debe intercambiar constantemente la imagen en pantalla: la persona docente, las diapositivas de la presentación y la temática en estudio.

Da el pase a un centro universitario para escuchar la respuesta a la pregunta planteada.

Presenta datos sobre la OIT, relacionados con el trabajo infantil.

La persona docente debe escuchar con atención los comentarios de los estudiantes.

La persona docente realimenta el comentario del estudiantado sobre derechos de la niñez.

Indica que por falta de tiempo no se ahonda en el tema.

Usa imágenes de Mafalda, vinculadas al tema.

\section{Implicación en términos de mediación pedagógica}

Brinda una visión general de los temas que se van a desarrollar.

Ubica al estudiantado en el contexto histórico antes de profundizar en la temática.

Aporta y comenta contenidos relevantes de la temática.

Refuerza conceptos.

Profundiza las temáticas con el uso de imágenes y figuras.

Responde a varios estilos de aprendizaje, ya que los gestos ayudan al estudiantado que son muy visuales.

Usa esquemas para presentar los conceptos o temas de estudio en la videoconferencia.

Alterna en pantalla la imagen de la persona docente y la diapositiva con los temas o conceptos en estudio, lo cual le da un poco de dinamismo a la videoconferencia.

Incorpora actividad interactiva.

Se interesa por presentar información actual al estudiantado y los incentiva para que investiguen.

Valora la participación y el criterio del estudiantado.

Aporta nueva información para aclarar o reforzar los temas de estudio.

Requiere más tiempo en algunas temáticas.

Utiliza las tiras cómicas para ilustrar el tema en estudio.

Finaliza con la frase de un bloguero: "La mayor pobreza es la soledad".

Menciona que el correo electrónico no aparece en la Faltó información importante para que el estudiantado puepresentación. da plantear sus consultas.

Fuente: Elaboración propia (2019).

\section{3- Registrando el proceso mediante el diario del investigador}

Se evidencia en los resultados obtenidos las situaciones que se le presentaron a la persona investigadora en cada una de las etapas realizadas, incluyendo las emociones, actitudes, anécdotas, formas de actuar y disposición por parte de los tutores para participar en la investigación. A continuación, se describen algunas de las expresiones relevantes recolectadas: 
Tabla 3

Expresiones relevantes de los tutores del Programa de Estudios Generales

Tutor

"La videoconferencia es un espacio privilegiado, digo yo, para humanizar".

“Ya uno piensa: '¿Cómo me peino?', '¿cómo me visto?'; o sea, un montón de elementos que juegan un papel ahí ¿verdad? Porque, a final de cuentas, vos sos el marco de la videoconferencia y tenés que dar la mejor imagen posible".

"Me obliga a ser más creativa; lo obliga a uno a estudiar, a ponerse a buscar más material; uno quiere, de alguna forma, tratar de transmitir las cosas de una forma más fresca, ¿verdad?"

"Yo trato de imprimirle ánimo; yo trato con mi voz de transmitir eso porque al final de cuentas no solo es el recurso visual: también es transmitir esa pasión, ese gusto, como las ganas".

"De cómo este país tiene que avanzar en el tema del uso de tecnologías de la información en educación. De que estamos atrasados, que es una tarea pendiente, que tenemos muchísimo por hacer y, bueno, es un reto. Simplemente, hay que ir para adelante e imitar buenas experiencias que se están llevando a cabo en otros países".

"Vamos hacia la era de la virtualización; hay que hacerlo de la forma más humana posible; podemos perder ese elemento, que es el central. El ser humano tiene que ser el centro de todo; pero ese reto implica modernización".

"Me trato de cuidar mucho, de cuidar mucho que la calidad debe mantenerse, no solo en la elaboración de la videoconferencia, sino el día que se va a hacer la videoconferencia estar uno hasta de ánimo; estar uno bien, 'con las pilas puestas'; estar dispuesto en la voz, la postura. Yo trato de cuidar esos detalles".

A "La UNED tiene que resolver el tema de la cantidad de tiempo que se asigna. Imagínese que son 16 horas; eso es totalmente falso: el tiempo que usted dura desplazándose, brindando la videoconferencia como tal, planeándola, haciendo el Power Point, completando todos los documentos que hay que enviarles a ustedes para seguir el protocolo y todo lo demás. Eso es mucho más tiempo".

"La capacitación es necesaria también para mejorar".

"La variedad de recursos que uno utiliza para mediar la clase; es importante que no sea siempre lo mismo, que sean diferentes, que como sea retador para el estudiante".

"A mí sí me gusta innovar y claro [que] para eso estamos; pero sí necesitamos un poco de apoyo".

"Tenemos que incentivar más la participación y eso. Yo puedo hacer bonita la videoconferencia, dinámica; pero ese es un apoyo, una ayuda de los centros".

"Aunque ellos opinen, yo hago un cierre; pero después de que ellos hablaron y todo. Pero para mí no es lo ideal que sea yo la que tenga que hablarles; es un espacio para que la voz de ellos se escuche para ver qué piensan ellos de la historia de lo que está pasando en la actualidad, de las problemáticas que le[s] atañen a ellos... este... y a través de las cuales me doy cuenta de los intereses particulares de ellos como jóvenes, como estudiantes".

"La capacitación es necesaria para mejorar y tal vez no solo a nivel tecnología, sino también a nivel meramente pedagógico" (Profesor A, comunicación personal, 7 de julio del 2014).

"Lo veo en la videoconferencia: la calidad de las preguntas. La calidad de las preguntas es muy pobre; la intervención de los estudiantes es muy pobre".

"Yo he estado en videoconferencia cuando les he dicho en la unidad tal y escucho un ruido y es que están rompiendo el plástico del libro. Entonces, qué más evidencia que no van preparados para aprovechar la herramienta que se les está dando".

"Yo incluso ahora les estaba explicando o les hice el comentario este: que aprovechen la tutoría. Que aprovechen la tutoría. No es sustitutiva la videoconferencia de la tutoría: son complementarias".

"Se los decía seguro en algún momento de las tutorías o la videoconferencia: que se sientan y ponen el celular y como no suena, se estresan porque '¿Qué pasará? ¿Se habrá caído internet?' Entonces, no están dedicándole realmente el tiempo necesario al estudio. Entonces, están desaprovechando los apoyos que se les dan, incluso la videoconferencia".

"Yo les doy la videoconferencia muy llana, muy conversado. Conversando con ellos... este... muy natural. Entonces, creo que eso es importante porque uno, repito, porque uno no sabe si del otro lado está un adolescente o un joven de 17 años".

"Hay momentos que me encantan. A mí me encanta cuando preguntan y se viene aquella lluvia de preguntas".

"Y me decía L: 'de ese uno por ciento, ¿cuántos dan videoconferencias? Muy poquitos, ¿verdad?' Entonces, lo hace a uno decir: 'Sí. Estoy haciendo algo interesante, algo importante".

Nota: Se anota L para resguardar la identidad del encargado de cátedra.

"Si... este... el facilitador tiene que estar también conectado ¿verdad?... este... con la actividad porque si nada más se trata de conectar el salón ¿verdad? No... El estudiante sí ocupa tener a alguien ahí que lo esté supervisando, [que] le esté ayudando". Profesor B, comunicación personal, 13 de julio del 2014). 
Expresión relevante

"La presentación Power Point, que es otra cosa valiosísima para mí en lo personal, es un bagaje de años".

"La profesionalización, incluso, pasaría por que el tutor o el profesor no fuera ni siquiera el responsable directo de aparecer en cámaras. ¿Acaso somos bonitos? Y no tenemos que serlo y no tenemos por qué hablar bien. No. ¿No podrán ser presentadores?"

"El tutor tendría la responsabilidad de preparar el guion".

C "Yo insisto en que ahora que se están colgando en internet, esa es la imagen de la Universidad Estatal a Distancia de Costa Rica, no la española. Está proyectando internacionalmente. Debería ser un producto lo mejor elaborado posible".

"La videoconferencia está para esto. La respuesta ideal del estudiante es esta".

"Es un reto, un desafío para cualquier docente el ser capaz de interesar al estudiante".

"Los estudiantes hacen muy pocas preguntas o no hacen ninguna pregunta y eso es porque probablemente no entendieron nada" (Profesor C, comunicación personal, 19 de junio del 2014).

"Muchas veces, los docentes no preparan sus contenidos de manera didáctica".

"La videoconferencia es uno de los recursos didácticos con que cuenta la UNED para comunicarse de manera masiva con los estudiantes". "El problema es que, a pesar de ser un recurso tecnológico que pretende ser una posible media-

D ción, termina convirtiéndose en un recurso muy magistral".

"Los estudiantes suelen ser muy tímidos y la participación del mediador (centro universitario-videoconferencia) es bastante rígida".

"Debe estimularse la participación, la criticidad de la información y no tanto la recepción" (Profesor D, comunicación personal, 11 de agosto del 2014).

Fuente: Elaboración propia (2019).

\section{4- Compartiendo ideas, criterios y sugerencias mediante la entrevista}

Los datos recopilados en esta etapa permitieron profundizar, por primera vez, en la percepción y experiencia de las personas docentes con respecto al uso de la videoconferencia, lo cual resultó muy enriquecedor porque cada una de ellas contó con el espacio para compartir sus anécdotas, experiencias o ideas que han acumulado a lo largo del tiempo.

Además, en el espacio se logró obtener información sumamente valiosa relacionada con los elementos técnicos y pedagógicos que las personas tutoras consideran de gran relevancia incluirlos en la propuesta del uso de la videoconferencia como recurso para la mediación pedagógica; se puntualizan seguidamente: 
TABLA 4

Elementos para la propuesta

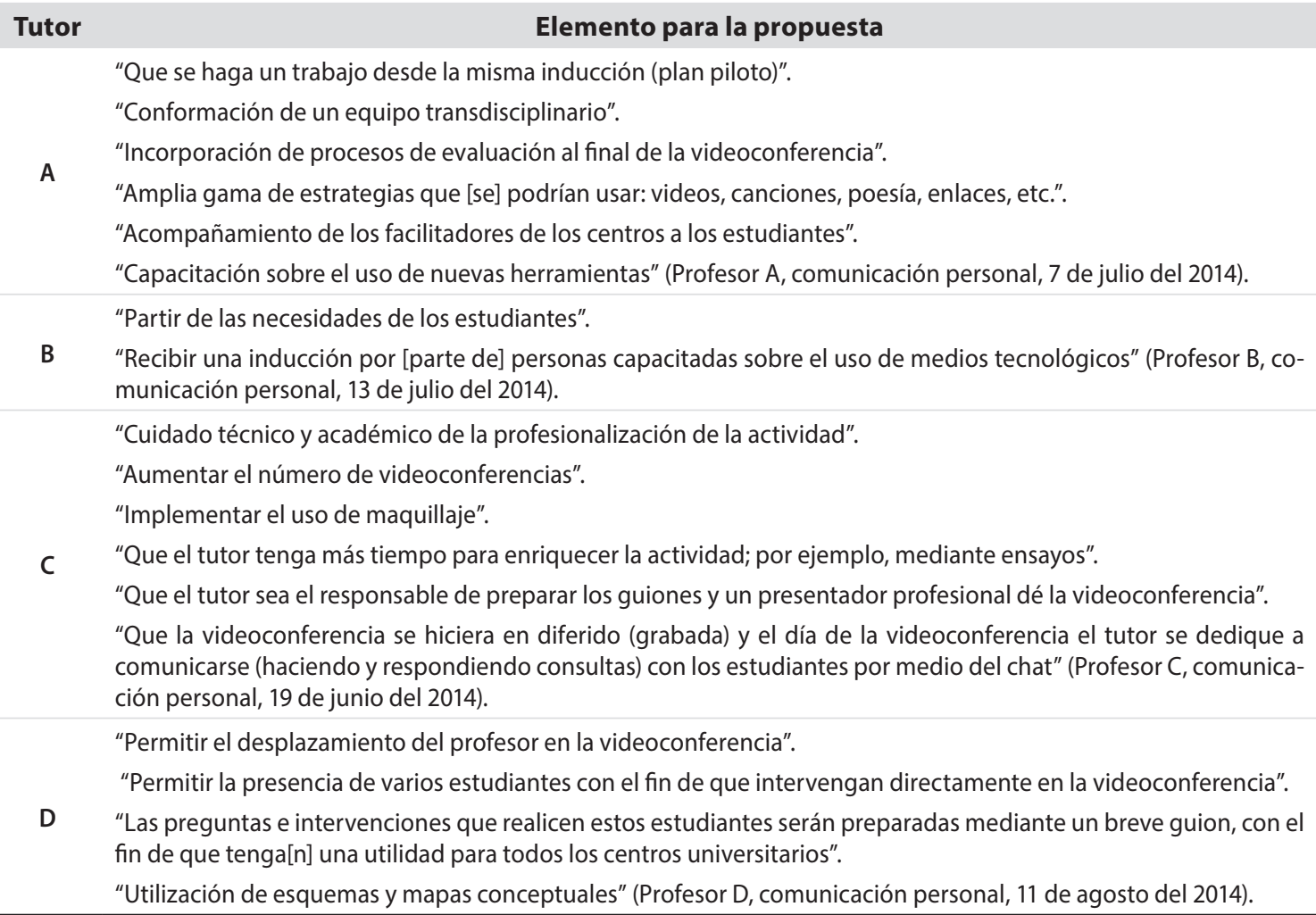

Fuente: Elaboración propia (2019).

De acuerdo con la información que se muestra en la tabla 4, las personas docentes consideran fundamental la existencia de elementos que serán clave para la elaboración de la propuesta. Se enfatiza en elementos pedagógicos como el uso de canciones, poesías o videos, lo mismo que la incorporación de mapas conceptuales o esquemas, tomando siempre en cuenta las necesidades del estudiantado. Mientras, para otros es fundamental la incorporación de criterios técnicos como la implementación de procesos de inducción y ensayos; recomendaciones para que la persona docente se pueda desplazar en el escenario durante la videoconferencia; el uso de grabaciones en diferido; la incorporación de maquillaje y conformar un equipo transdisciplinario con el fin de contar con el criterio de varios especialistas (persona encargado de cabina, persona docente, persona productora y persona diseñadora gráfica) para realizar y mediar de forma efectiva la videoconferencia. 


\section{5- Compartiendo experiencias con un colega}

Para el proceso la información recolectada fue crucial porque permitió contar con la opinión de una persona docente, quien analizó, implementó y evalúo los criterios técnicos y pedagógicos considerados en la propuesta preliminar para mejorar el proceso de mediación pedagógica.

Por lo tanto, la persona colega, como resultado de su experiencia, reflexión y puesta en marcha de la propuesta preliminar compartió las observaciones y recomendaciones que se evidencian a continuación:

TABLA 5

Resultados de la validación de la propuesta

\section{Observaciones}

1. "La persona docente indica que le parecen acertados los criterios técnicos y pedagógicos que se encuentran en la propuesta preliminar".

2. "Menciona que aprueba el hecho de que se incluyan, en la propuesta preliminar, recomendaciones para los actores (persona docente, estudiantado, personal técnico, personas facilitadoras) que intervienen en la videoconferencia".

3. "Se requiere más acompañamiento por parte de las personas que se encuentran en la sala y cabina".

4. "Los objetivos que se plantearon para la realización de la videoconferencia tenían como meta lograr la participación del estudiantado".

\section{Recomendaciones}

1. "La implementación en la videoconferencia de ejercicios para la elaboración de la tarea".

2. "Grabar la videoconferencia con antelación para tener la oportunidad de hacer las modificaciones necesarias antes de presentarla al estudiantado y el día que está programada la realización de la videoconferencia, la persona docente se dedica a atender la parte interactiva y responder las consultas del estudiantado".

3. "Asignar más tiempo en las cargas académicas para la planificación, ejecución y evaluación de la videoconferencia".

4-. "Considera importante que la persona productora le consulte a la persona docente cómo le fue en la videoconferencia, si contó con todo el material, el apoyo y el soporte técnico para desarrollar la videoconferencia o si necesita que la persona productora o el personal técnico mantenga[n] factores o acciones que han dado buen resultado (las fortalezcas) o las modifiquen para mejorar la calidad de las videoconferencias".

5. "Se requiere más apoyo por parte de las personas facilitadoras de los centros universitarios".

5. "Piensa que es necesario que se sienten responsabilidades en las personas facilitadoras de los centros universitarios".

6. "Es fundamental que la persona docente reciba una inducción previa y se le brinden espacios para que pueda realizar ensayo(s) previo(s)".

6. "La persona productora debe verificar si la persona encargada de cabina y el de piso están cumpliendo con las indicaciones que se dejan para cada materia. En el caso de que se variara, es necesario que lo justifiquen para que la productora pueda realizar las modificaciones que se requieren".

7. "Se requiere la participación del estudiantado para que la videoconferencia no se convierta en un proceso unidireccional".

7. "Es necesario que la persona facilitadora de los centros universitarios fomente la participación. Sin embargo, si no lo consigue, que colabore leyendo al aire las respuestas".

8. "Que se asigne un porcentaje a la tarea que tenga relación con los contenidos desarrollados en la videoconferencia".

9. "Que se apliquen encuestas a los estudiantes, las cuales ayuden a analizar y mejorar las videoconferencias".

Fuente: Elaboración propia (2019). 


\section{PROPUESTA PRELIMINAR ELABORADA}

Con el fin de promover la mediación pedagógica apropiada para la realización de una videoconferencia y generar en el estudiantado estrategias de aprendizaje, surge la idea de diseñar una propuesta de uso de la videoconferencia para la mediación como respuesta y guía para las personas docentes, la cual contiene elementos técnicos y pedagógicos fundamentales a la hora de planificar las sesiones programadas. Seguidamente, se detalla la propuesta:

Propuesta preliminar

\begin{tabular}{|c|}
\hline \multicolumn{1}{|c}{ Técnicos } \\
\hline 1. Se requiere profesionalizar la actividad. Se podría: \\
1.1. Implementar maquillaje para los profesores. \\
1.2. Contratar a una persona comunicadora/presen- \\
tadora para que imparta las videoconferencias.
\end{tabular}

2. Dedicar espacios dentro de la agenda del Programa de Videoconferencia para que la persona docente realice ensayos previos.

3. Asignar espacios para que la persona docente graben previamente la videoconferencia.

4. Implementar nuevos recursos para presentar los contenidos; por ejemplo: uso de Flash, pizarra interactiva y Prezi, entre otros.

5. Facilitarle a la persona docente una computadora o tablet para que pueda revisar el blog en vivo.

6. Brindar más tiempo para elaborar el material que se va a utilizar en la videoconferencia.

7. Recibir capacitación sobre lineamientos gráficos para la elaboración de Power Point.

8. Capacitar sobre el uso adecuado del escenario para definir si realiza la exposición de pie, sentado o de ambas maneras

9. Recibir y atender al estudiantado, entregarles el material, orientarlos y acompañarlos durante la videoconferencia (los facilitadores de los centros universitarios).

10..Incorporar videos, canciones o poesías para apoyar o ilustrar los contenidos en estudio.

12. Implementar el uso de escenarios virtuales para las grabaciones y las videoconferencias.

13. Incorporar nuevas estrategias que generen la participación del estudiantado conectados en el blog.

14. Contar con una persona colega que le ayude a atender las consultas que el estudiantado anota en el chat del blog.

15. Cuidar la imagen personal, la postura, el estado de ánimo y los tonos de voz al realizar una videoconferencia.

\section{Mediación pedagógica}

1. Presentar durante la videoconferencia puntos claves y ejemplos cotidianos para que el estudiantado pueda asociarlos con los conocimientos previos (aprendizaje significativo).

2. Ser capaz despertar el interés en el estudiantado para que participe.

3. Brindar espacios para que el estudiantado realicen sus consultas.

4. Anticipar al estudiantado los principales contenidos que se van a abordar.

5. Usar y explicar esquemas o mapas conceptuales.

6. Mostrar imágenes alusivas a los temas tratados.

7. Recapitular ideas principales.

8. Ofrecer ejemplos para una mejor comprensión del tema.

9. Presentar síntesis de los temas abordados.

10. Promover la discusión de los saberes.

11. Negociar y discutir los saberes con el estudiantado.

12. Proporcionar espacios y materiales para la construcción del aprendizaje.

13. Tomar en cuenta los conocimientos previos del estudiantado.

14. Promover la negociación, discutir, compartir y reconstruir saberes con el estudiantado.

15. Promover en el estudiantado nuevo interpretaciones de los conocimientos y la creación de nuevos significados (aprendizaje significativo).

16. Vincular al estudiantado con los valores, la información y las habilidades previstas en el plan de estudios. 


\begin{tabular}{|c|c|}
\hline \multicolumn{2}{|c|}{ Propuesta preliminar } \\
\hline Técnicos & Mediación pedagógica \\
\hline & $\begin{array}{l}\text { 17. Comprender la forma en que el estudiantado aprenden, sus } \\
\text { dificultades, necesidades e intereses. }\end{array}$ \\
\hline & $\begin{array}{l}\text { 18. Conocer el contenido disciplinario y establecer conexiones } \\
\text { entre los conceptos. }\end{array}$ \\
\hline & 19. Conocer estrategias didácticas y evaluativas. \\
\hline & $\begin{array}{l}\text { 20. Conocer bien la función de las TIC en el Programa de Estudios } \\
\text { Generales que la Universidad ofrece. }\end{array}$ \\
\hline & $\begin{array}{l}\text { 21. Relacionar las ideas con lo que el estudiantado ya sabe (apren- } \\
\text { dizaje significativo). }\end{array}$ \\
\hline & $\begin{array}{l}\text { 22. Formar parte de un equipo transdisciplinario, cuya misión es } \\
\text { buscar las mejores estrategias y materiales que le permita me- } \\
\text { diar eficientemente la videoconferencia. }\end{array}$ \\
\hline & 23. Generar procesos de evaluación dentro de la videoconferencia. \\
\hline & 24. Promover procesos de investigación en las videoconferencias. \\
\hline \multicolumn{2}{|c|}{ Función del estudiante } \\
\hline & $\begin{array}{l}\text { 1. Posee conocimiento, y también la libertad y la voluntad para } \\
\text { participar. }\end{array}$ \\
\hline & 2. Tiene una actitud favorable a la comprensión del tema. \\
\hline & 3. Adquiere el conocimiento con la ayuda del docente. \\
\hline & 4. Valora a sus pares como personas. \\
\hline & $\begin{array}{l}\text { 5. Es capaz de cuestionarse críticamente las temáticas } \\
\text { abordadas. }\end{array}$ \\
\hline
\end{tabular}

Nota: quien llevó a cabo la investigación reconoce, a partir de la revisión literaria, que puede ampliarse el tema; pero por motivos de tiempo y recursos, solo se asumen estos aspectos.

\section{CONCLUSIONES}

Como se desprende de los resultados, las personas docentes propusieron recomendaciones, estrategias metodológicas y técnicas, las cuales sirvieron de insumo para la elaboración de la propuesta preliminar. Por lo tanto, se cumplió el objetivo específico relacionado con la temática.

De igual forma, la información recolectada por medio de la entrevista a la persona docente de la cátedra de Trabajo Social permitió analizar, implementar y evaluar si realmente los criterios técnicos y pedagógicos considerados en la propuesta preliminar le permitieron mejorar el proceso de mediación en la videoconferencia impartida y, consecuentemente, la calidad académica. Adicionalmente, se incorporaron las sugerencias y recomendaciones en el replanteamiento de la propuesta, de modo que se cumplió con la totalidad de objetivos propuestos para la investigación.

Los resultados obtenidos en la investigación son claves para la mediación pedagógica de las videoconferencias debido a que, gracias a la propuesta preliminar, la persona docente cuenta con una guía que le ayudará a la planificación de la actividad, aprovechando estrategias metodológicas diferentes y acordes a la edad y las necesidades del estudiantado, entre otros factores pertinentes.

Cabe mencionar que, respecto del estado de la cuestión, se evidencia que las necesidades de las personas docentes con respecto a la inducción y capacitación son similares a las de las personas docentes que participaron en la investigación. 
Un aspecto relevante es que en ambos casos se reconoce la importancia de este recurso tecnológico tanto para la mediación pedagógica como para el aprendizaje del estudiantado, siempre que se aproveche adecuadamente y que las instituciones donde se implementa destinen los recursos necesarios para minimizar el impacto de los factores evidenciados en las investigaciones citadas.

La metodología que se implementó en la investigación fue muy enriquecedora, puesto que permitió conocer las inquietudes y sugerencias de las personas docentes, las cuales fueron tomadas como insumos valiosos para la elaboración de la propuesta preliminar.

\section{RECOMENDACIONES}

En primer lugar, se sugiere realizar un taller participativo posterior a la presentación de la propuesta preliminar, en el que las personas docentes puedan evaluarla, analizarla y, de ser necesario, modificarla de acuerdo con los aspectos que consideren pertinentes. Además, en el desarrollo del taller se podría usar una videoconferencia grabada para que los asistentes con la propuesta en mano puedan valorar si el documento requiere alguna modificación a fin de mejorar la medación pedagógica.

En segundo lugar, es necesario que las personas tutoras incluyan en sus planeamientos de videoconferencia los elementos técnicos y pedagógicos que se encuentran en la propuesta (guía) para la mediación pedagógica.

En tercer lugar, se recomienda revisar con cierta periodicidad los aspectos técnicos y pedagógicos que se encuentran en la propuesta preliminar, debido a que la tecnología se actualiza constantemente, la formación de la persona docente es continua, los contenidos se remozan y las necesidades del estudiantado varían a pasos agigantados.

En cuarto lugar, en el Programa de Videoconferencia de la UNED se debe establecer una guía para que las personas tutoras la consulten e incorporen al planeamiento de cada una de las sesiones programadas.

En quinto lugar, elementos clave como: a) la formación profesional que les permita aplicar los conocimientos adquiridos con respecto a aspectos técnicos, gráficos y pedagógicos que intervienen en la investigación y b) las alternativas viables para la asignación y distribución de trabajo y tiempo para que la persona docente pueda planificar, desarrollar, evaluar y replantear las sesiones de videoconferencia, son algunos de los subtemas de esta investigación que pueden estudiarse en el futuro para mejorar la calidad de las videoconferencias. 


\section{REFERENCIAS}

Álvarez, E.; Ochoa, R.; Salado, L. y Soto, R. (2013). La interacción de factores del modelo de videoconferencia y su influencia en el proceso de enseñanza-aprendizaje. Revista Internacional Administración \& Finanzas (6).

Bonfill, C. (2007, julio). Clases virtuales a través de videoconferencias: factores críticos vivenciados por los tutores en un sistema de Educación a Distancia. Temas de Management. (5).

Contreras, l. (1995). De la enseñanza a la mediación pedagógica ¿cambio de paradigma o cambio de nombre. Revista Educación, 19. San José: Universidad de Costa Rica.

Gutiérrez, F. y Prieto, D. (1999). La mediación pedagógica: apuntes para una educación a distancia. Buenos Aires: Ediciones Ciccus-La Crujía.

Hernández, R. Fernández, C. y Baptista, P. (2008). Metodología de la investigación. (4a ed.). México, D. F.: McGraw Hill.

Medinnus, G. (1990). Estudio y observación del niño. México, D.F.: Limusa.

Salazar, S. (2012). El conocimiento pedagógico del contenido como modelo de mediación docente. San José: Coordinación Educativa y Cultural Centroamericana (CECC/SICA).

Sandí, M. (2003). Investigación cualitativa en educación. Fundamentos tradiciones. España: McGraw-Hill.

Taylor, S. y Bogdan, R. (1996). Introducción a los métodos cualitativos de investigación. España: Paidós.

Universidad Estatal a Distancia (2007). Modelo Pedagógico. San José: UNED.

Para citar este documento:

Salas, S. (2020). Percepciones de las personas docentes para el mejoramiento de la mediación pedagógica en el uso de videoconferencias en la Universidad Estatal a Distancia (UNED). Revista Innovaciones Educativas. 22(32). 105-121. DOI: https://doi.org/10.22458/ ie.v22i32.2992 